\section{Antipathy towards people with personality disorders}

The paper by Chartonas et al ${ }^{1}$ gives understandable data but its title obscures a great deal of change since 1988. When Lewis \& Appleby's paper ${ }^{2}$ was published the title alone was sufficient for many to give a nod of agreement without reading further. But there is a big difference between the patients seen by psychiatrists, often as emergencies, and the rest of the population who have personality disorder. Chartonas et al ${ }^{1}$ also note that around $50 \%$ of people in secondary care services have personality disorder, yet I am sure it would be quite untrue to say that psychiatrists dislike half their patients.

The main trouble with our current diagnostic system for personality disorder is that it is hardly ever used. Only borderline and antisocial (dissocial) get a mention in official statistics, together with mixed personality disorder or 'personality disorder - not otherwise specified', an abject admission of diagnostic failure if ever there was one. In the proposed revised ICD-11 classification the key element that helps to define the patients psychiatrists dislike is severity of personality disturbance. ${ }^{3}$ Only a tiny proportion of patients have severe personality disorder - probably less than $2 \%$ - but they create a great deal of trouble for services, having disproportionately greater contacts than others. ${ }^{4}$

At milder levels of personality disorder there is much greater acceptance of personality disturbance by all practitioners, and at some levels there may be a better response to treatment ${ }^{5}$ than in patients with no personality disturbance, as there is good adherence to treatment yielding superior results. ${ }^{6}$ In the new classification, the level of severity is qualified by up to five trait domains: negative affective, disinhibited, dissocial, detached and anankastic. ${ }^{3}$ It is when the first three of these are prominent at the level of severe personality disorder that antipathy may be created in the minds of psychiatrists. Until we can get away from the notion that personality disorder is just a synonym for havoc, the stigma of the diagnosis will persist. The new classification should show that only a relatively small number of us are free from personality disturbance at some level, and this is the best antidote to stigma I know.

Peter Tyrer, Emeritus Professor of Community Psychiatry, Imperial College London, UK; email: p.tyrer@imperial.ac.uk

P.T. is Chair of the World Health Organization ICD-11 Revision Group for the Classification of Personality Disorders.

1 Chartonas D, Kyratsous M, Dracass S, Lee T, Bhui K. Personality disorder: still the patients psychiatrists dislike? BJPsych Bull 2017; 41: 12-7.

2 Lewis G, Appleby L. Personality disorder: the patients psychiatrists dislike. Br J Psychiatry 1988; 153: 44-9.

3 Tyrer P, Reed GM, Crawford MJ. Classification, assessment, prevalence and effect of personality disorder. Lancet 2015; 385: 717-26.

4 Yang M, Coid J, Tyrer P. Personality pathology recorded by severity: national survey. Br J Psychiatry 2010; 197: 193-9.

5 Sanatinia R, Wang D, Tyrer P, Tyrer H, Crawford M, Cooper S, et al. Impact of personality status on the outcomes and cost of cognitive behaviour-therapy for health anxiety. Br J Psychiatry 2016; 209: 244-50.

6 Tyrer P, Wang D, Tyrer H, Crawford M, Cooper S. Dimensions of dependence and their influence on the outcome of cognitive-behaviour therapy for health anxiety: randomised controlled trial. Personal Ment Health 2016; 10: 96-105.

doi: $10.1192 / p b .41 .2 .122$ 